\title{
The Association of Distinct Social Determinants of Health with Added Sweetener Knowledge and Consumption in a U.S. Sample of People Living with HIV
}

\author{
Emma M. Kileel ${ }^{1} \cdot$ Kirsten A. Dickins $^{2} \cdot$ Hui Zheng ${ }^{3} \cdot$ Kathleen V. Fitch $^{4} \cdot$ Sara E. Looby $^{5}$
}

Accepted: 15 October 2021 / Published online: 3 November 2021

(c) The Author(s) 2021

\begin{abstract}
Prior studies in people living with HIV (PLWH) suggest added sweetener intake exceeds recommendations and associates with cardiometabolic abnormalities. Little is known of factors that associate with increased sweetener consumption in PLWH. This cross-sectional study explored knowledge and consumption of added sweeteners and associations of social determinants of health (SDoH) among 900 PLWH residing in the United States. Demographics, SDoH, and added sweetener knowledge and consumption were assessed via an online survey, multivariable analyses were completed. Results demonstrate that sex, race, and low educational level associated with lower sweetener knowledge. Race, age, body mass index, income, limited access to fresh fruits/vegetables, and low sweetener knowledge associated with higher sweetener consumption. Findings highlight the need for consideration of specific demographics and inequitable social circumstances when developing nutrition lifestyle strategies, inclusive of added sweetener education, that are feasible and sustainable across diverse community settings of PLWH.
\end{abstract}

Keywords HIV $\cdot$ Sweetening agents $\cdot$ Social determinants of health

\section{Resumen}

Estudios previos en personas que viven con el VIH (PLWH) sugieren que la ingesta adicional de edulcorantes excede las recomendaciones y se asocia con anomalías cardiometabólicas. Poco se sabe de los factores que se asocian con un mayor consumo de edulcorantes en PLWH. Este estudio transversal exploró el conocimiento y el consumo de edulcorantes agregados y las asociaciones de los determinantes sociales de la salud (SDoH) entre 900 PLWH que residen en los Estado Unidos. Lo datos demográficos, $\mathrm{SDoH}$, y en conocimiento y el consumo de edulcorantes añadidos se evaluaron mediante una encuesta en línea y se completaron análisis multivariables. Los resultados demuestran que el sexo, la raza y el bajo nivel educativo

Kathleen V. Fitch and Sara E. Looby have contributed equally.

Sara E. Looby

slooby@partners.org

1 Metabolism Unit, Massachusetts General Hospital, Boston, MA, USA

2 Yvonne L. Munn Center for Nursing Research, Massachusetts General Hospital, Boston, MA, USA

3 Biostatistics Center, Massachusetts General Hospital, Boston, MA, USA

4 Metabolism Unit, Massachusetts General Hospital and Harvard Medical School, Boston, MA, USA

5 Metabolism Unit and the Yvonne L. Munn Center for Nursing Research, Massachusetts General Hospital and Harvard Medical School, 55 Fruit Street LON 207, Boston, MA 02114, USA 
se asocian con un menor conocimiento sobre edulcorantes. Raza, edad, índice de masa corporal, ingresos, acceso limitado a frutas/verduras frescas y conocimiento bajo sobre edulcorantes asociado con un mayor consumo edulcorantes. Los hallazgos resaltan la necesidad de considerar la demografía específica y las circunstancias sociales desiguales al desarrollar estrategias de estilo de vida nutricional, incluida la educación adicional sobre edulcorantes, que sean factibles y sostenibles en diversos entornos comunitarios de PLWH.

\section{Introduction}

Weight gain and obesity have emerged as contemporary health concerns in people living with HIV (PLWH) engaged in treatment [1-3] and may in part be related to poor diet and increased consumption of added sweeteners. In the United States, increased intake of added sweeteners, both naturally occurring and artificial, may influence the development of adverse cardiometabolic conditions including obesity, diabetes, and cardiovascular disease (CVD) [4-8].

Studies pertinent to HIV and sweeteners are limited, though findings suggest that sweetener consumption is increased among PLWH compared to people without HIV, and negative clinical correlates are associated with sweetener consumption in PLWH. Hall et al. demonstrated that PLWH, compared to adults without HIV, had higher intake of total sugar and added sugar, as well as the artificial sweetener, aspartame, which was associated with coronary plaque [9]. Tiozzo et al. showed that PLWH with metabolic syndrome consumed $19 \%$ of daily calories from added sugar and PLWH without metabolic syndrome consumed $15 \%$ of daily calories from added sugar. In this study, both groups (PLWH with and without metabolic syndrome) exceeded added sugar intake recommendations, suggesting that increased intake of added sugar may contribute to hyperglycemia and higher rates of metabolic syndrome in PLWH [10]. Findings from a large cohort study of women with HIV suggested a higher percentage of total daily caloric intake from "sweets" (including cookies, cakes, candy, sweetened cereals) was associated with increased insulin resistance [11]. However, these studies did not explore factors that might influence added sweetener consumption in PLWH, nor did they examine if lack of knowledge about added sweeteners associates with sweetener consumption.

Many PLWH experience disproportionate social and economic burden [12], and demonstrate sub-optimal adherence to dietary guidelines [13]. Understanding factors that influence added sweetener knowledge and consumption in PLWH may help inform educational curriculums integrated into nutritional interventions for this population. The primary objective of this cross-sectional survey study was to explore added sweetener knowledge and consumption in a U.S. sample of PLWH. As a sub-objective, we investigated factors which may associate with added sweetener knowledge and consumption including social determinants of health $(\mathrm{SDoH})$.

\section{Methods}

\section{Design and Participants}

An anonymous online survey was conducted among a U.S. sample of PLWH between February 2019 and January 2020. A variety of recruitment strategies were employed to ensure outreach to PLWH of diverse sex, race, and ethnicity. Participants were recruited in the United States via an advertisement that included a link to the study survey. Upon accessing the survey, participants were prompted to attest to eligibility criteria including age at least 18 years, residing in the United States, and being HIV positive (see Supplemental Material 1 for the participant flow chart). Study advertisements in English and Spanish were posted on online platforms for organizations and publications known to the HIV community including: The Well Project, Adelante, Positively Aware, The Body, and HIV Plus; and social media: Twitter, Facebook, and Craigslist. Other outreach strategies included a collaboration with The Henne Group, an organization that distributes email communications with study information to a panel of PLWH, and a mass-mailing of study postcards and flyers that included the survey link and a scannable quick response (QR) code sent to over 40 HIV community organizations, health centers, and hospitals throughout the United States. People living with HIV in attendance at health fairs or meetings at HIV community organizations proximal to the study investigators in Massachusetts were also invited to complete the survey via tablet.

\section{Measures}

\section{Survey Development}

The survey was developed by the study investigators using adapted versions of previously published valid and reliable questionnaires to assess: demographic and clinical characteristics, SDoH [14], sweetener knowledge [15], and sweetener consumption [16-18]. For this study, added sweeteners included both naturally occurring sugars and artificial sweeteners (aspartame, saccharin, sucralose, among others). Prior to survey development, a focus group consisting of a diverse community sample of PLWH was conducted to solicit feedback on the survey content for clarity and length, online usability, and appeal of study advertisements [19]. Based on findings from the focus group, the final survey 
was refined to 33 multiple choice and open-ended questions (Supplemental Material 2).

The survey was hosted on the web-based platform Partners Rally, developed by Partners HealthCare Research and the Massachusetts General Hospital Laboratory of Computer Science (https://rally.partners.org/about). The survey was available in English and Spanish. All data were collected by participant self-report.

\section{Sweetener Knowledge and Consumption}

Consistent with methods from a prior sweetener knowledge study in people without HIV [15], a cumulative total sweetener knowledge score was established. Sweetener knowledge was assessed via 11 questions, correct answers were assigned a value of 1 and incorrect answers were assigned value of 0 . The total possible sweetener knowledge score ranged from 0 to 11 , with a higher score indicating greater knowledge. For analysis purposes, sweetener knowledge score was treated as a continuous variable.

Sweetener consumption was assessed via 13 questions. Continuous total sweetener consumption scores were computed for the following: total food consumption, total drink consumption, and total consumption (which included total food plus total drink consumption). Participants were provided a list of food and drink items and prompted to rate consumption as usually/often (weighted as 2), sometimes (weighted as 1), or rarely/never (weighted as 0). Scores were summed and the total possible score range for each variable was: total food consumption $0-12$, total drink consumption $0-14$, and total consumption 0-26; higher scores indicated greater consumption. For analysis purposes sweetener consumption score was treated as a continuous variable.

\section{Demographic, Social, and Clinical Characteristics}

Demographic and HIV clinical data including age (years), sex at birth, gender identity, race, ethnicity, duration of HIV (years), co-morbid conditions, current antiretroviral therapy (ART) use, and HIV viral load (detectable/undetectable) were collected (Supplemental Material 2). Additionally, SDoH were assessed, specifically, health literacy, food security, housing stability, and financial resources [14]. Participants were asked to report current weight and height, and body mass index (BMI) was calculated using standard calculations and assessed according to established obesity parameters [20]. The survey item related to ART adherence was adapted from the Center for Adherence Support Evaluation Adherence Index [21].

\section{Study Outcomes and Covariates}

The study outcomes were respondent knowledge and consumption of added sweeteners. The association of SDoH, age, sex, race, and BMI with added sweetener knowledge and consumption was evaluated.

\section{Statistical Analysis}

The Shapiro-Wilk test was used to assess normality; nonnormally distributed continuous variables are presented as median (lower quartile [Q1], upper quartile [Q3]) and categorical variables as frequencies and percentages.

Univariate analyses were performed to evaluate the relationship between explanatory variables including: sex, race, educational attainment, age, health literacy ("Can you understand health information provided from a doctor, nurse or clinic?", yes/no), and sweetener knowledge score using a linear regression model. Univariate analyses were also conducted to assess the relationship between the following variables: sex, race, age, BMI, income, food security ("Do you have access to fresh fruit and vegetables?", yes/no), and sweetener consumption score using a linear regression model.

Variables with significant associations with each outcome in the univariate models were selected for placement in multivariable models. The variable, "Can you understand the health information provided from your doctor, nurse or clinic?" was excluded from the multivariable model for total sweetener knowledge due to evidence of multicollinearity between this variable and educational attainment. Additionally, 99\% of respondents answered "Yes" to this question. For the purpose of the multivariable analyses race represents Black or African American, Asian, American Indian or Alaskan Native, Native Hawaiian or other Pacific Islander, more than one race, or other, education represents $<$ high school diploma or GED versus $\geq$ high school diploma or GED, annual income represents $<\$ 25,000$ versus $\geq \$ 25,000$ based on 2020 Poverty Guidelines [22] and the variable "access to fresh fruits and vegetables" was grouped to all of the time/some of the time versus never. Multivariable linear regression modeling was performed with sweetener knowledge score and sweetener consumption score as separate dependent variables and $95 \%$ confidence intervals were computed to determine significant independent associations within each model. Data were downloaded from Partners Rally to Excel ${ }^{\circledR}$ and exported to JMP® Pro 13 (Cary, NC) statistical software for analysis, inference was based on a nominal significance level $(\mathrm{p} \leq 0.05)$. 


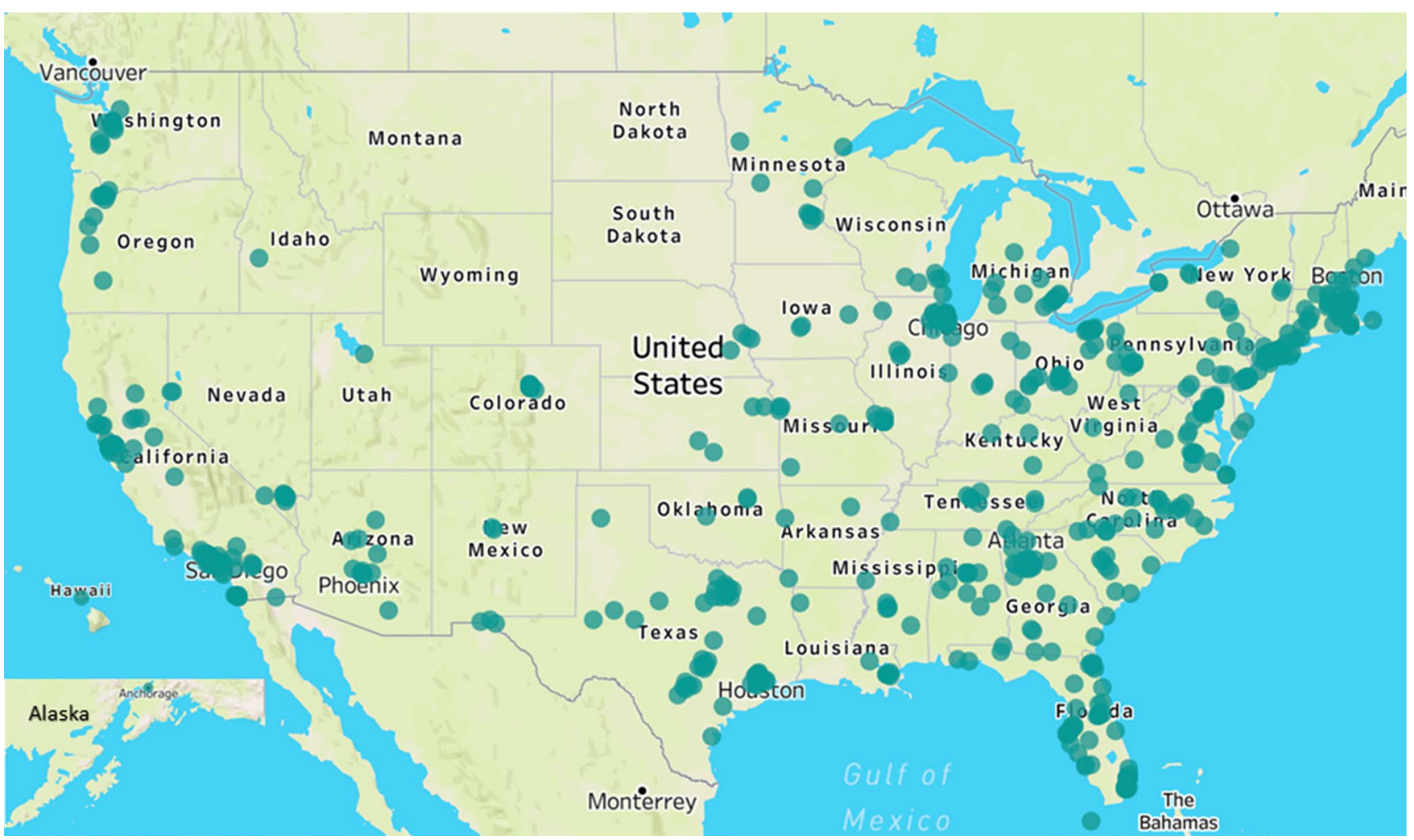

Fig. 1 Location of residence of respondent by zip code. Alaska and Hawaii moved for illustrative purposes. Missing zip codes $=43$

\section{Power Calculation}

For the primary study outcome, it was estimated that with a minimum of 800 participants, we would be able to construct a 95\% confidence interval for the true proportion of correct responses regarding added sweetener knowledge with a width of 0.03 (i.e., $0.32 \pm 0.03)=(0.29,0.35)$. Nine-hundred respondents completed the survey.

\section{Results}

\section{Demographic and Clinical Characteristics}

Respondents resided in 46 of 52 U.S. states and territories; Fig. 1 illustrates location of residence by zip code. Demographic and clinical characteristics of the survey respondents are summarized in Table 1. The median age of the respondents was 54 years (lower quartile [Q1], upper quartile [Q3]: 44, 60 years), $80 \%$ reported male natal sex, $97 \%$ identified as cisgender, 22\% were Black or African American, 13\% identified as Hispanic/Latino. Regarding clinical characteristics, $71 \%$ were overweight or obese, the median number of years living with HIV was $18(9,27), 93 \%$ of respondents reported having an undetectable HIV viral load and 98\% reported current treatment with ART. The median number of comorbidities (hypertension, hyperlipidemia, cancer, CVD, pre-diabetes, diabetes, asthma) reported among the respondents was $1(0,2)$.

\section{Social Determinant of Health Characteristics}

Table 2 summarizes SDoH characteristics. Sixty-five percent of respondents reported educational attainment beyond high school/GED, and $64 \%$ of respondents reported an annual income between $\$ 1$ and $\$ 49,999$. Over $90 \%$ of respondents reported current health insurance enrollment, stable housing, and the ability to understand information provided by a healthcare provider.

Responses pertaining to food security are presented in Table 2. Approximately one quarter of respondents reported eating less in the last year because there was not enough money for food. Similarly, $31 \%$ of respondents reported having access to fresh fruits and vegetables only some of the time versus all of the time or never.

\section{Sweetener Knowledge and Consumption}

Sweetener knowledge and consumption scores are shown in Table 3. Median sweetener knowledge score was $8(7,9)$ of a total possible score range of $0-11$. The median total sweetener consumption score was $9(6,12)$. Evaluating sweetener 
Table 1 Demographic and clinical characteristics

\begin{tabular}{ll}
\hline & $n(\%)$ or median $(\mathrm{Q} 1, \mathrm{Q} 3)$ \\
\hline & Total \\
& $n=900$ \\
& $54(44,60)$ \\
Age (years) & $724(80 \%)$ \\
Natal sex & \\
Male & $867(97 \%)$ \\
Gender identity* & $29(3 \%)$ \\
Cisgender & \\
Non-cisgender & $194(22 \%)$ \\
Race & $609(68 \%)$ \\
Black or African American & $8(<1 \%)$ \\
White & $8(<1 \%)$ \\
Asian & $2(<1 \%)$ \\
American Indian or Native Alaskan & \\
Native Hawaiian or other & $41(5 \%)$ \\
Pacific Islander & $38(4 \%)$ \\
Other & $114(13 \%)$ \\
More than one race & $27.4(24.3,31.7)$ \\
Hispanic ethnicity & \\
BMI (kg/m ${ }^{2}$ ) & $261(29 \%)$ \\
BMI category & $337(38 \%)$ \\
$<25 \mathrm{~kg} / \mathrm{m}^{2}$ & $295(33 \%)$ \\
$\geq 25-30 \mathrm{~kg} / \mathrm{m}^{2}$ (overweight) & $1(0,2)$ \\
$\geq 30 \mathrm{~kg} / \mathrm{m}^{2}$ (obese) & $18(9,27)$ \\
Number of comorbidities & $839(93 \%)$ \\
Duration of HIV (years) & \\
Undetectable HIV viral load & \\
Current ART use & \\
\hline & \\
&
\end{tabular}

$A R T$ antiretroviral therapy, $B M I$ body mass index

*Non-cisgender includes participants identifying as transgender, gender queer, gender variant, and 'other'. Missing gender identity data, $n=4$

$¥ 7$ BMI data points not included: Missing data, $n=5$ Outlier data, $n=2$ removed due to erroneous height and weight data that yielded inaccurate BMI calculation $\left[2.35 \mathrm{~kg} / \mathrm{m}^{2}\right.$ and $10.18 \mathrm{~kg} / \mathrm{m}^{2}$ ]

${ }^{ \pm}$Missing ART data, $n=22$

consumption delineated by food and drink intake, median total food consumption score was $5(4,7)$, and median total drink consumption score (excluding alcohol) was $3(2,5)$.

\section{Associations with Demographics, Social Determinants of Health, and Sweetener Knowledge}

In univariate analyses (Table $4 a)$, female sex ( $\beta$ estimate $-0.41 ; 95 \% \mathrm{CI}-0.55,-0.26$; F ratio $30.59 ; \mathrm{p}<0.0001)$, race $(\beta$ estimate $-0.75 ; 95 \% \mathrm{CI}-0.86,-0.63 ; \mathrm{F}$ ratio $163.46 ; \mathrm{p}<0.0001)$, having less than a high school diploma/GED ( $\beta$ estimate $-0.92 ; 95 \%$ CI $-1.34,-0.49$; $\mathrm{F}$ ratio $18.02 ; \mathrm{p}<0.0001)$, and not understanding information provided by a health provider or clinic ( $\beta$ estimate
$-0.97 ; 95 \%$ CI $-1.49,-0.44 ; \mathrm{F}$ ratio $13.00 ; \mathrm{p}=0.0003$ ) were negatively associated with sweetener knowledge score, while age ( $\beta$ estimate $0.02 ; 95 \%$ CI $0.01,0.03 ; \mathrm{F}$ ratio $15.71 ; \mathrm{p}<0.0001)$ was positively associated with sweetener knowledge score. In the multivariable model (Table $4 \mathrm{a})$, female sex ( $\beta$ estimate -0.16 ; $95 \%$ CI -0.30 , $-0.02 ; \mathrm{F}$ ratio $5.19 ; \mathrm{p}=0.02)$, race $(\beta$ estimate -0.68 ; $95 \% \mathrm{CI}-0.80,-0.56$; F ratio $120.78 ; \mathrm{p}<0.0001)$, and having less than a high school diploma/GED ( $\beta$ estimate $-0.61 ; 95 \%$ CI $-1.00,-0.21$; F ratio $9.00 ; p=0.003$ ) each remained significantly associated with lower total sweetener knowledge score $\left(R^{2}=0.17\right.$; F ratio 46.06; $\mathrm{p}<0.0001)$.

\section{Associations with Demographics, Social Determinants of Health, and Sweetener Consumption}

In the univariate analyses (Table $4 \mathrm{~b})$, female sex ( $\beta$ estimate $0.75 ; 95 \%$ CI $0.37,1.13 ; \mathrm{F}$ ratio $15.27 ; \mathrm{p}=0.0001)$, race $(\beta$ estimate $1.37 ; 95 \%$ CI $1.05,1.68 ; \mathrm{F}$ ratio 74.45 ; $\mathrm{p}<0.0001)$, BMI ( $\beta$ estimate $0.07 ; 95 \%$ CI 0.03, 0.11; F ratio $10.26 ; \mathrm{p}=0.001$ ), annual income $<\$ 25,000$ ( $\beta$ estimate 1.00; 95\% CI 0.69, 1.31; F ratio 41.22; $\mathrm{p}<0.0001)$, and never having access to fresh fruits and vegetables ( $\beta$ estimate $3.49 ; 95 \%$ CI $2.29,4.69$; F ratio 32.56 ; $\mathrm{p}<0.0001)$ were all positively associated with total sweetener consumption score. Sweetener knowledge ( $\beta$ estimate $-0.73 ; 95 \%$ CI $-0.89,-0.57$; F ratio $77.29 ; \mathrm{p}<0.0001)$ (Supplemental Material 3) and age ( $\beta$ estimate -0.12 ; 95\% CI $-0.14,-0.09$; F ratio 88.88; p < 0.0001 ) were negatively associated with sweetener consumption score. In the multivariable analysis (Table $4 \mathrm{~b})$, race ( $\beta$ estimate $0.53 ; 95 \%$ CI $0.20,0.87 ; \mathrm{F}$ ratio $9.77 ; \mathrm{p}=0.002)$, age $(\beta$ estimate $-0.10 ; 95 \%$ CI $-0.12,-0.07 ; \mathrm{F}$ ratio 62.39 ; $\mathrm{p}<0.0001)$, BMI ( $\beta$ estimate $0.05 ; 95 \%$ CI 0.01, 0.09; F ratio 5.04; $\mathrm{p}=0.03$ ), annual income $<\$ 25,000$ ( $\beta$ estimate 0.69; 95\% CI 0.40, 0.99; F ratio 21.24; $\mathrm{p}<0.0001$ ), never having access to fresh fruits and vegetables ( $\beta$ estimate 2.73 ; $95 \%$ CI 1.58, 3.87; F ratio 21.88; $\mathrm{p}<0.0001)$, and low sweetener knowledge score $(\beta$ estimate $-0.43 ; 95 \%$ $\mathrm{CI}-0.60,-0.26$; F ratio 24.51; $\mathrm{p}<0.0001)$ all remained significant predictors of total sweetener consumption $\left(R^{2}\right.$ $=0.21 ; \mathrm{F}$ ratio 33.67; $\mathrm{p}<0.0001)$.

Sensitivity analyses were performed for each outcome (sweetener knowledge and sweetener consumption), including the variable, told by a healthcare provider you have diabetes (yes: $n=134 / 900 ; 15 \%$ ) in each multivariable model. Having diabetes was not a significant predictor of sweetener knowledge ( $\beta$ estimate $0.01 ; 95 \%$ CI $-0.14,0.17$; F ratio $0.03 ; \mathrm{p}=0.87$ ) or sweetener consumption ( $\beta$ estimate 0.33 ; $95 \% \mathrm{CI}-0.06,0.73 ; \mathrm{F}$ ratio $2.84 ; \mathrm{p}=0.09)$. 
Table 2 Social determinants of health characteristics

\begin{tabular}{|c|c|}
\hline & $n(\%)$ \\
\hline & $\begin{array}{l}\text { Total } \\
n=900\end{array}$ \\
\hline \multicolumn{2}{|l|}{ Highest level of education } \\
\hline Less than a high school/GED & $17(2 \%)$ \\
\hline High school/GED & $294(33 \%)$ \\
\hline Post high school/GED & $589(65 \%)$ \\
\hline \multicolumn{2}{|l|}{ Income level } \\
\hline$\$ 1-\$ 49,999$ & $572(64 \%)$ \\
\hline$\$ 50,000-\$ 99,999$ & $212(24 \%)$ \\
\hline$\$ 100,000$ and greater & $116(13 \%)$ \\
\hline \multicolumn{2}{|l|}{ Reported health insurance } \\
\hline Yes & $850(94 \%)$ \\
\hline \multicolumn{2}{|l|}{ Reported stable housing } \\
\hline Yes & $854(95 \%)$ \\
\hline \multicolumn{2}{|c|}{ Can you understand the health information provided from your doctor, nurse or clinic? } \\
\hline Yes & $889(99 \%)$ \\
\hline \multicolumn{2}{|c|}{$\begin{array}{l}\text { In the last year did you ever eat less than you felt you should because there wasn't enough } \\
\text { money for food? }\end{array}$} \\
\hline Yes & $236(26 \%)$ \\
\hline \multicolumn{2}{|c|}{ Do you have access to fresh fruit and vegetables? } \\
\hline All of the time? & $608(68 \%)$ \\
\hline Some of the time? & $278(31 \%)$ \\
\hline Never? & $14(2 \%)$ \\
\hline \multicolumn{2}{|c|}{ Do you have a place to store and cook food? } \\
\hline All of the time? & $843(94 \%)$ \\
\hline Some of the time? & $51(6 \%)$ \\
\hline Never? & $6(<1 \%)$ \\
\hline
\end{tabular}

Table 3 Sweetener knowledge and consumption scores

\begin{tabular}{ll}
\hline & Median (Q1, Q3) \\
\hline $\begin{array}{l}\text { Total } \\
n=900\end{array}$ \\
$\begin{array}{l}\text { Total knowledge score } \\
\text { Sweetener Consumption Scores }\end{array}$ \\
$\begin{array}{l}\text { Total consumption score } \\
\text { Total food consumption score }\end{array}$ & $8(7,9)$ \\
Total drink consumption score & $9(6,12)$ \\
\hline
\end{tabular}

*Possible knowledge score range $0-11$, with a higher score indicating greater knowledge

${ }^{¥}$ Possible consumption score range 0-26. Possible food consumption score: $0-12$. Possible drink consumption score (without alcohol): $0-14$. Higher scores indicate greater consumption

\section{Discussion}

In a geographically diverse, U.S.-based sample of 900 PLWH, we demonstrate that key demographics and SDoH are important factors associated with added sweetener knowledge and consumption. Factors including sex, race, age, BMI, education, income, and access to fresh fruits and vegetables associated with lower sweetener knowledge and higher sweetener consumption in PLWH. Further, lower sweetener knowledge was associated with higher sweetener consumption. These findings highlight the need for consideration of these specific factors when developing patientcentered nutrition lifestyle strategies that are feasible and sustainable across diverse community settings of PLWH.

In our study, lower educational attainment correlated with lower sweetener knowledge and lower sweetener knowledge was associated with higher added sweetener consumption, even when controlling for SDoH. Level of educational attainment has been directly linked with important health outcomes including life expectancy in the general population [23]. In the United States, across 


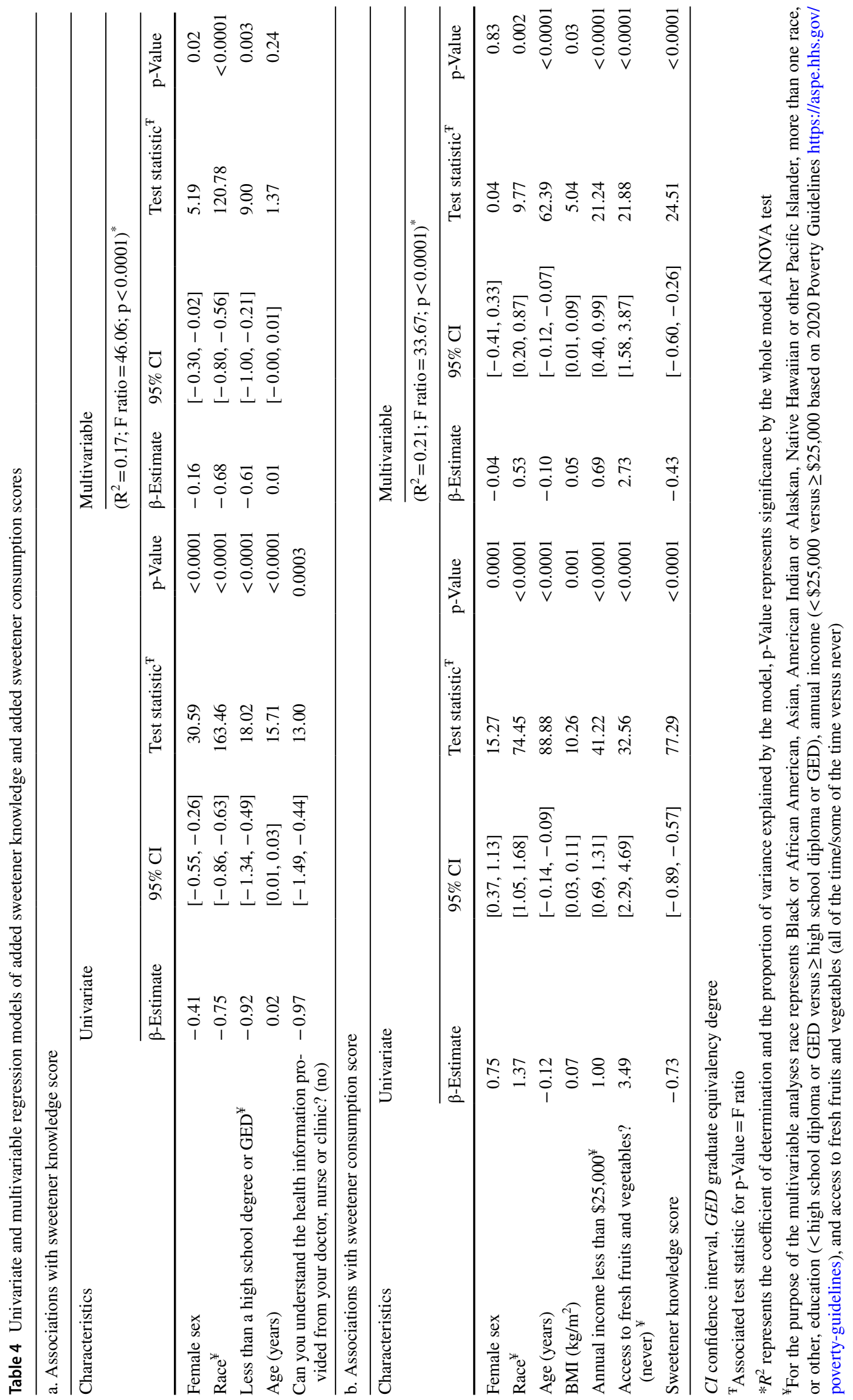


racial/ethnic backgrounds, adults with lower educational attainment are more likely to report worse health outcomes [24]. Higher educational attainment is often associated with higher earning employment opportunities offering health benefits, which may positively impact one's ability to purchase more nutritious food $[25,26]$. Also, individuals with higher educational attainment are more likely to have higher health literacy and understanding of recommendations regarding nutrition and healthy dietary behaviors. To our knowledge, no prior studies have accounted for educational attainment when designing dietary modification interventions in PLWH. Nutrition interventions may be more effective if customized to account for educational attainment to facilitate successful comprehension of instructions and resources to modify added sweetener consumption.

Co-morbidities, including overweight or obesity, diabetes, and CVD, are common in many PLWH, owing to traditional and non-traditional factors associated with HIV infection [27, 28]. BMI associated with added sweetener consumption in this cohort. Given what is known about the potential effects of added sweeteners on cardiometabolic health in PLWH [9], establishing lifestyle modification interventions that include education on added sweetener intake to successfully modify risk in PLWH is important. Also, existing nutrition-based lifestyle modification interventions for PLWH may have not been developed based on evidence specifically derived from PLWH, including pertinent data on SDoH that can impact behavior change and knowledge on healthy eating. Our findings suggest this is an important consideration when establishing feasible and successful nutritional interventions to meet the unique needs of PLWH.

Reduced access to fresh fruits and vegetables associated with increased added sweetener consumption. This finding may imply that respondents with decreased access to fruits and vegetables may be replacing more nutritious, lower calorie foods with less nutritious, more calorie-dense foods with added sweeteners. Reduced intake of fresh fruits and vegetables in the general population has been correlated with the development of several non-communicable diseases, including CVD [29-31]. Palar et al. evaluated an intervention that aimed to provide healthy food and snacks to PLWH and type 2 diabetes with food insecurity. This intervention resulted in improved consumption of healthy fats, fresh fruits, and vegetables, and decreased depression and binge drinking in PLWH [32]. These findings highlight how dietary interventions designed to improve access to healthy foods may effectively reduce health complications. Many PLWH endure the burden of multi-morbidity and disparate social challenges that often stem from limited financial resources [12]. Creating structural changes that improve access to healthy foods, including fresh fruit and vegetables, among PLWH may help decrease intake of added sweeteners, enhance engagement in health-promoting dietary patterns, and decrease the incidence of comorbidities in this population.

Many campaigns to educate and increase awareness of the deleterious effects of added sweeteners and help curtail the obesity epidemic have been launched in the general population by U.S. and state-based agencies [33, 34]. To our knowledge, a study evaluating the effectiveness of these campaigns on reducing added sweetener intake in PLWH has not been published. Thus, it is difficult to ascertain whether existing interventions intended to reduce added sweetener consumption are effective or need to be tailored for PLWH. If an intervention were to be designed to improve added sweetener knowledge and reduce added sweetener consumption in PLWH exclusively, findings from this study support that it should be: 1 . Written and presented in plain language and piloted among PLWH (including robust enrollment of women) from differing educational backgrounds so it can be adapted to meet the needs of all levels of educational attainment; 2 . Culturally sensitive for racially and ethnically diverse individuals; 3 . Comprised of dietary recommendations that are accessible to income disparate PLWH living in varied community settings; and 4 . Inclusive of content that describes the relationship between added sugar consumption and obesity, and the association of obesity with increased risk for the development of CVD and diabetes-conditions that are already prevalent in many PLWH.

\section{Limitations}

This study used an online survey to evaluate added sweetener knowledge and consumption among a large geographically diverse sample of PLWH. While this method was appropriate to achieve the aims of this investigation, there are limitations. First, as with all survey data that is dependent upon participant self-report, responses are subject to the potential for recall bias and social desirability bias. Although the study advertisement was targeted to PLWH and individuals needed to attest to being HIV-positive, it cannot be confirmed that all respondents were diagnosed with HIV. In addition to online advertisements, adjunctive recruitment methods including printed flyers and post cards were distributed at community HIV organizations and health centers. However, study participation was limited to those who could access the survey via the internet which may have led to selection bias, resulting in a respondent cohort not generalizable to all PLWH in the US. The study did not include a comparison group of individuals without HIV, and this limited the ability to decipher whether our findings among PLWH are unique when compared to individuals without HIV. Lastly, significant effort was extended to advertise and partner with local and national HIV organizations to ensure equal respondent representation from diverse racial/ethnic backgrounds, sex, income, and educational levels. While the 
number of women enrolled in our study is higher than that of other U.S.-based HIV studies, our overall study samplealbeit representative of participant demographics in other HIV studies [35, 36]—had limited diversity of sex, race/ethnicity, and other sociodemographic variables, which limits the generalizability of findings.

\section{Conclusions}

This novel survey study illustrates knowledge and consumption of added sweeteners among a cohort of 900 PLWH living in the United States. Importantly, findings expose distinct sociodemographic factors including sex, race, educational attainment, and aspects of food security that associate with lower added sweetener knowledge and higher consumption in PLWH. These findings support the establishment of nutrition-based lifestyle interventions that are inclusive of added sweetener education and tailored to meet diverse demographic, educational, and social needs of PLWH. Given that increasing rates of cardiometabolic indices are observed in PLWH, and more recently among those taking integrase strand transfer inhibitors [37] our results also have public health relevance. Specifically, findings emphasize the need for policies aimed to mitigate barriers to healthy food access to improve overall nutritional intake, health, and quality of life among PLWH.

Supplementary Information The online version contains supplementary material available at https://doi.org/10.1007/s10461-021-03508-1.

Acknowledgements The authors would like to acknowledge the survey respondents, Rebecca Schnall PhD, MPH, RN-BC, FAAN, Mary Dickey Lindsay Associate Professor of Disease Prevention and Health Promotion Columbia University; Holly Marie Parker, Laboratory and Computer Science at Massachusetts General Hospital/Partners Rally; Jeffrey C. Henne and Sergio Garcia Gallegos of the Henne Group; and Jason Fairchild, Creative Director, Truesdale Group, Recycled Paper Printing, Inc.

Author Contributions KVF and SEL were responsible for conceptualizing the study including development of the methodology, secured resources by obtaining grant funding, provided leadership, were responsible for supervision of the research staff, and wrote the original draft and oversaw revisions of the manuscript. KVF, SEL, EMK, $\mathrm{KAD}$, and $\mathrm{HZ}$ contributed to the development of the study's methodology, conducted the formal analysis including the development of coding associated with the software, and contributed to the original draft and revision of the manuscript.

Funding This work was supported by the Nutrition and Obesity Research Center of Harvard, Pilot and Feasibility Grant: NIH Grant P30 DK40561. Conflicts of interest/Competing interests: EMK, $\mathrm{KAD}$, and $\mathrm{HZ}$ report no financial interests or potential related conflicts of interest. KVF has received support from an educational grant from Gilead Sciences, Inc. unrelated to this project. SEL is a non-paid board member of the non-profit organization Healing Our Community Collaborative, Inc. Boston, MA, and has received 1-time speaker fees from the Association of Nurses in AIDS Care in 2017 and 2019, unrelated to this project.

Data Availability All data are available from the corresponding author upon request.

\section{Declarations}

Ethical Approval All study procedures and materials were approved by the Partners Institutional Review Board.

Consent to Participate A description of the study was provided on the landing page for the online survey and consent was implied by survey completion. Identifiable information was not collected in the survey and participants did not receive remuneration for study participation.

Consent for Publication All authors have reviewed the work and given consent for publication of this manuscript in AIDS and Behavior.

Open Access This article is licensed under a Creative Commons Attribution 4.0 International License, which permits use, sharing, adaptation, distribution and reproduction in any medium or format, as long as you give appropriate credit to the original author(s) and the source, provide a link to the Creative Commons licence, and indicate if changes were made. The images or other third party material in this article are included in the article's Creative Commons licence, unless indicated otherwise in a credit line to the material. If material is not included in the article's Creative Commons licence and your intended use is not permitted by statutory regulation or exceeds the permitted use, you will need to obtain permission directly from the copyright holder. To view a copy of this licence, visit http://creativecommons.org/licenses/by/4.0/.

\section{References}

1. Sax PE, Erlandson KM, Lake JE, et al. Weight gain following initiation of antiretroviral therapy: risk factors in randomized comparative clinical trials. Clin Infect Dis. 2019. https://doi.org/10. 1093/cid/ciz999.

2. Koethe JR, Jenkins CA, Lau B, et al. Rising obesity prevalence and weight gain among adults starting antiretroviral therapy in the United States and Canada. AIDS Res Hum Retrovir. 2016;32(1):50-8.

3. Gallant J, Hsue PY, Shreay S, Meyer N. Comorbidities among US patients with prevalent HIV infection-A trend analysis. J Infect Dis. 2017;216(12):1525-33.

4. Yang Q, Zhang Z, Gregg EW, Flanders WD, Merritt R, Hu FB. Added sugar intake and cardiovascular diseases mortality among US adults. JAMA Intern Med. 2014;174(4):516-24.

5. Azad MB, Abou-Setta AM, Chauhan BF, et al. Nonnutritive sweeteners and cardiometabolic health: a systematic review and meta-analysis of randomized controlled trials and prospective cohort studies. CMAJ. 2017;189(28):E929-39.

6. Dhingra R, Sullivan L, Jacques PF, et al. Soft drink consumption and risk of developing cardiometabolic risk factors and the metabolic syndrome in middle-aged adults in the community. Circulation. 2007;116(5):480-8.

7. Johnson RK, Appel LJ, Brands M, et al. Dietary sugars intake and cardiovascular health: a scientific statement from the American Heart Association. Circulation. 2009;120(11):1011-20.

8. Nettleton JA, Lutsey PL, Wang Y, Lima JA, Michos ED, Jacobs DR Jr. Diet soda intake and risk of incident metabolic syndrome 
and type 2 diabetes in the Multi-Ethnic Study of Atherosclerosis (MESA). Diabetes Care. 2009;32(4):688-94.

9. Hall LN, Sanchez LR, Hubbard J, et al. Aspartame intake relates to coronary plaque burden and inflammatory indices in human immunodeficiency virus. Open Forum Infect Dis. 2017;4(2):ofx083.

10. Tiozzo E, Konefal J, Adwan S, et al. A cross-sectional assessment of metabolic syndrome in HIV-infected people of low socioeconomic status receiving antiretroviral therapy. Diabetol Metab Syndr. 2015;7:15.

11. Hessol NA, Ameli N, Cohen MH, Urwin S, Weber KM, Tien PC. The association between diet and physical activity on insulin resistance in the Women's Interagency HIV Study. J Acquir Immune Defic Syndr. 2013;62(1):74-80.

12. Gant Z, Lomotey M, Hall HI, Hu X, Guo X, Song R. A countylevel examination of the relationship between HIV and social determinants of health: 40 States, 2006-2008. Open AIDS J. 2012;6:1-7.

13. Weiss JJ, Sanchez L, Hubbard J, Lo J, Grinspoon SK, Fitch KV. Diet quality is low and differs by sex in people with HIV. J Nutr. 2019;149(1):78-87.

14. Health Leads. Social needs screening tooklit. 2016. https://healt hleadsusa.org/wp-content/uploads/2016/07/Health-Leads-Scree ning-Toolkit-July-2016.pdf/. Accessed 16 Apr 2020

15. Tierney M, Gallagher AM, Giotis ES, Pentieva K. An online survey on consumer knowledge and understanding of added sugars. Nutrients. 2017. https://doi.org/10.3390/nu9010037.

16. Lin C, Zhang, Y, Carlton, ED, Lo, SC. 2014 FDA health and diet survey. Center for Food and Applied Nutrition Food and Drug Administration. 2016. https://www.fda.gov/media/96883/downl oad. Accessed May 52020.

17. National Health and Nutrition Examination Survey (NHANES) Food Frequency Questionnaire. 2004. https://www.cdc.gov/nchs/ data/nhanes/nhanes_03_04/tq_fpq_c.pdf. Accessed 16 Apr 2020.

18. Gans KM, Risica PM, Wylie-Rosett J, et al. Development and evaluation of the nutrition component of the rapid eating and activity assessment for patients (REAP): a new tool for primary care providers. J Nutr Educ Behav. 2006;38(5):286-92.

19. Kileel EM, Rivard C, Fitch KV, Looby SE. Eliciting perspectives of the key study population: an effective strategy to inform advertisement, content and usability of an online survey for a national investigation. Contemp Clin Trials Commun. 2020. https://doi. org/10.1016/j.conctc. 2020.100585 .

20. CDC. Centers for disease control and prevention: defining adult overwight and obesity. 2020. https://www.cdc.gov/obesity/adult/ defining.html/. Accessed 27 May 2020.

21. Mannheimer SB, Mukherjee R, Hirschhorn LR, et al. The CASE adherence index: a novel method for measuring adherence to antiretroviral therapy. AIDS Care. 2006;18(7):853-61.

22. US Department of Health and Human Services. 2020 poverty guidelines. 2019. https://aspe.hhs.gov/topics/poverty-economicmobility/poverty-guidelines/. Accessed 16 May 2020.

23. Olshansky SJ, Antonucci T, Berkman L, et al. Differences in life expectancy due to race and educational differences are widening, and many may not catch up. Health Aff. 2012. https://doi.org/10. 1377/hlthaff.2011.0746.

24. National Center for Health Statistics. Health, United States, 2011: with special feature on scioeconomic status and health. Report no: 2012-1232. Hyattsville (MD). 2012.

25. French SA, Wall M, Mitchell NR. Household income differences in food sources and food items purchased. Int J Behav Nutr Phys Act. 2010;7:77.

26. Julian T, Kominski R. Education and synthetic work-life earnings estimates. Washington, DC. 2011.

27. Smit M, Brinkman K, Geerlings S, et al. Future challenges for clinical care of an ageing population infected with HIV: a modelling study. Lancet Infect Dis. 2015;15(7):810-8.

28. Schouten J, Wit FW, Stolte IG, et al. Cross-sectional comparison of the prevalence of age-associated comorbidities and their risk factors between HIV-infected and uninfected individuals: the AGEhIV cohort study. Clin Infect Dis. 2014;59(12):1787-97.

29. Gan Y, Tong X, Li L, et al. Consumption of fruit and vegetable and risk of coronary heart disease: a meta-analysis of prospective cohort studies. Int J Cardiol. 2015;183:129-37.

30. Zhan J, Liu YJ, Cai LB, Xu FR, Xie T, He QQ. Fruit and vegetable consumption and risk of cardiovascular disease: a metaanalysis of prospective cohort studies. Crit Rev Food Sci Nutr. 2017;57(8):1650-63.

31. Tian Y, Su L, Wang J, Duan X, Jiang X. Fruit and vegetable consumption and risk of the metabolic syndrome: a meta-analysis. Public Health Nutr. 2018;21(4):756-65.

32. Palar K, Napoles T, Hufstedler LL, et al. Comprehensive and medically appropriate food support is associated with improved HIV and diabetes health. J Urban Health. 2017;94(1):87-99.

33. American Heart Association: Added Sugars: American Heart Association. 2018. https://www.heart.org/en/healthy-living/healt hy-eating/eat-smart/sugar/added-sugars. Accessed 5 May 2020.

34. Centers for Disease Control and Prevention. Get the facts: sugarsweetened beverages and consumption. 2017. https://www.cdc. gov/nutrition/data-statistics/sugar-sweetened-beverages-intake. html. Accessed 27 May 2020.

35. Curno MJ, Rossi S, Hodges-Mameletzis I, Johnston R, Price MA, Heidari S. A systematic review of the inclusion (or exclusion) of women in HIV research: from clinical studies of antiretrovirals and vaccines to cure strategies. J Acquir Immune Defic Syndr. 2016;71(2):181-8.

36. Castillo-Mancilla JR, Cohn SE, Krishnan S, et al. Minorities remain underrepresented in HIV/AIDS research despite access to clinical trials. HIV Clin Trials. 2014;15(1):14-26.

37. Eckard AR, McComsey GA. Weight gain and integrase inhibitors. Curr Opin Infect Dis. 2020;33(1):10-9.

Publisher's Note Springer Nature remains neutral with regard to jurisdictional claims in published maps and institutional affiliations. 